Article

\title{
Discovering New Rock Paintings at Shmsali and Gorgali Rock Shelters in Kohgiluye and Bouier Ahmad Province, Southern Iran
}

\section{Esmail Hemati Azandaryani ${ }^{1}{ }^{*}$, Hossein Qolami $^{2}$, Yaghob MohammadiFar $^{3}$ and Abass Razmposh ${ }^{4}$}

1 Department of archaeology, University of Bu-Ali Sina, Khaje Rashid Sq., 43 Hamedan, Iran

2 Department of Archaeology, University of Tehran, Tehran, Iran; E-Mail: hossein.arc@gmail.com

3 Department of archaeology, University of Bu-Ali Sina, Hamedan, Iran; E-Mail: yamohamadi@yahoo.com

4 Department of Archaeology, University of Mohaghegh-e Ardabili, Ardabil;

E-Mail: razmpoush.abbas@gmail.com

* Author to whom correspondence should be addressed; E-Mail: Hemati30 @ yahoo.com;

Tel.: 0098-918-714-5772

Academic Editor: Robert G. Bednarik

Received: 21 December 2014 / Accepted: 27 March 2015 / Published: 20 April 2015

\begin{abstract}
The Shamsali and Gorgali rock shelters were discovered during an archaeological survey in 2009 at Kohgiluye Bouier Ahmad province, west of Iran. In total, 50 paintings occur at both rock shelters; 21 at Shamsali, and 29 remains at Gorgali rock shelter. The paintings consist of "ibex", "Predators", and "riders" in red and black. They are depicted stylistically in singular or plural subjects in profile. In addition, the most numerous images in the Shamsali and Gorgali rock shelters represent "ibex", comparable with a large numbers of such motifs identified in other regions of Iran. There is no certainty in attributed dates, because we are lacking absolute dating methods.
\end{abstract}

Keywords: Iran; Kohgiluye Bouier Ahmad; Shamsali; Gorgali; rock painting

\section{Introduction}

The Pictograms are considered as one of the most notable artistic cultural remains in different fields of study, such as archaeology, history of art, social sciences, etc. Although the archaeological remains 
of caves and rock-shelters are more widely recognized in the western part of Iran under the current studies, only a few such rock art sites have been discovered so far, all of which are located in the Zagros Mountains. A considerable number of pictograms have been reported from different parts of Iran: Ghar-e Dushe [1-4], Kuhdasht-e Lorestan [5], Homian [6], Eshkaft-e Ahoo [7], Ghar-e Cheshme Sohrab [8], Abdozou Rock Shelter in Firouz Abad [9], Mir Malas in Louristan [10], Tang-e Tadavan Rock shelter and Tang-e Teyhooee Cave in Fars [11], Kuh-e-Donbeh in Isfahan [12], Helak in Fars province [13], North Khorasan province [14], and a Pictograph of Saravan (Sistan-Baluchistan) [15]. These sites contain plain geometric paintings, zoomorphic (animal-shaped) and human patterns, supposedly dating from the Paleolithic to the Sassanid era [1-8,13-21].

Archaeological investigation of Chin-Loudab in the area of the Bouyer-Ahmad Province were carried out by Hossein Qolami in the spring of 2008 where many archaeological sites were discovered, such as the Rock paintings of Eshkaft-e shamali and Eshkaft-e gorgali. These paintings are sometimes connected to each other (panels) and sometimes as individual figures (motifs).

\section{Shamsali Rock Shelter}

The Shamsali rock shelter is located at $150 \mathrm{~m}$, northwest of Kamak Nadali Village, suburb of Loudab County, Kohgiluye Bouier Ahmad Province (Figure 1). The rock shelter lies at an altitude of 1913 m and N 3432569 latitude, E 0480795 longitude. The rock shelter floor is smoothly sloped and is at the same level as peripheral fields and its entrance is sloped $45^{\circ}$ southwardly. The rock shelter is 9 $\mathrm{m}$ deep, $7.50 \mathrm{~m}$ wide, and $16 \mathrm{~m}$ tall (Figure 2), and opens eastwards. Various motifs are painted on the northern, northeastern, southwestern and western walls of the rock shelter, stylistically or naturally in "zoomorphic" and "anthropomorphic" forms in red and black. In total, 21 motifs were depicted in this rock shelter, which can be classified in two groups by color and location of the depiction. The first groups are red motifs that are located on the northern wall (Figure 3). Most of them are "ibexes" that are depicted singular or in flock. "Ibexes" are shown singly or in groups stylistically in profile position with long curved or jag-shaped horns, "predators" motifs are also shown alongside these motifs. These motifs are also shown stylistically which are observable in "ibex" motifs (Figure 4). Beside the motifs, which were mentioned earlier, there is a stylistic depiction of a horse rider who is hunting in a scene that is related to the other motifs (Figure 5). In the second group, the motifs are stylistically depicted in black paint on the west wall of the rock shelter. As in the first group, the collection is made up of "ibex" and armed horse rider motifs.

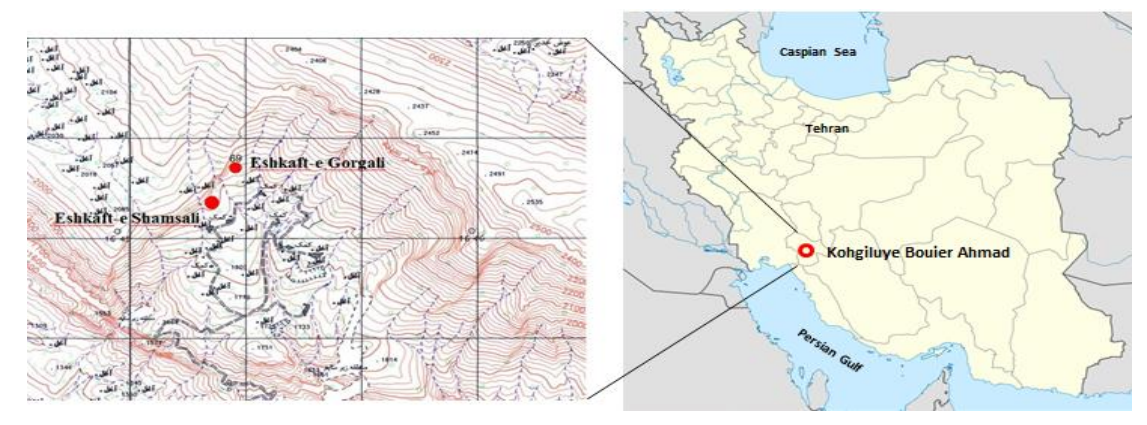

Figure 1. The location of rock shelters in Kohgiluye Bouier Ahmad province. 

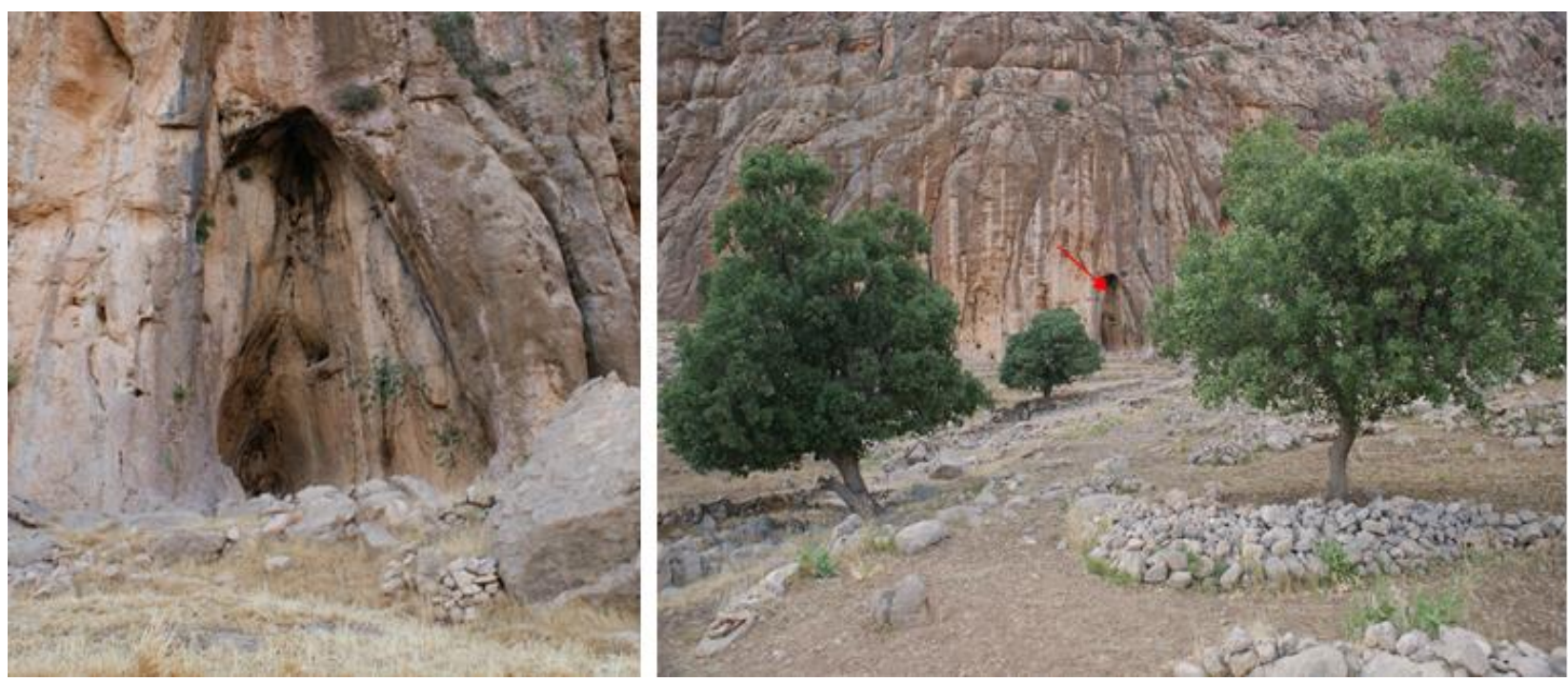

Figure 2. View of the Shamsali Rock shelter located $150 \mathrm{~m}$ northwest of Kamak Nadali Village.

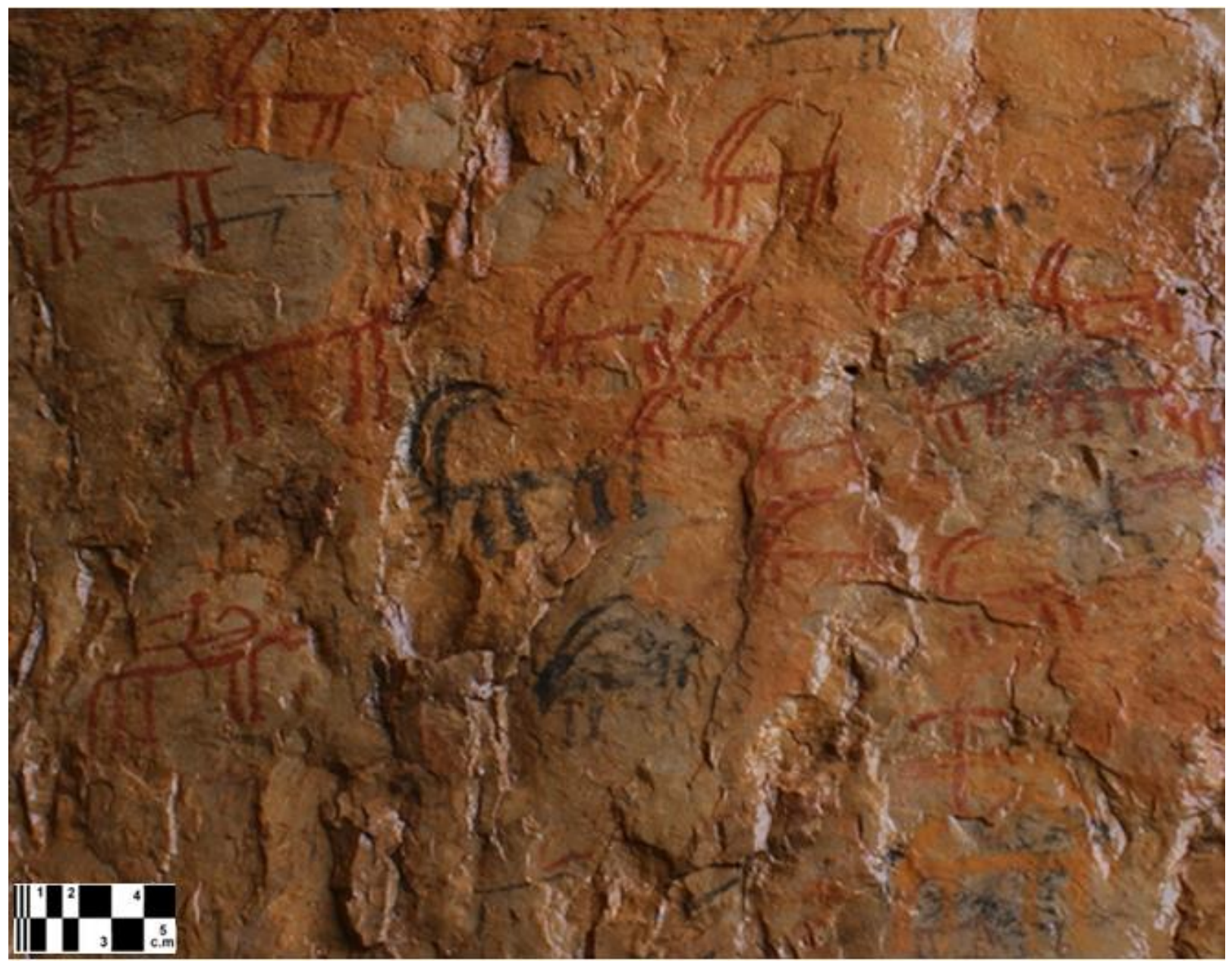

Figure 3. The main group of Pictograms in the Shamsali Rock shelter. 

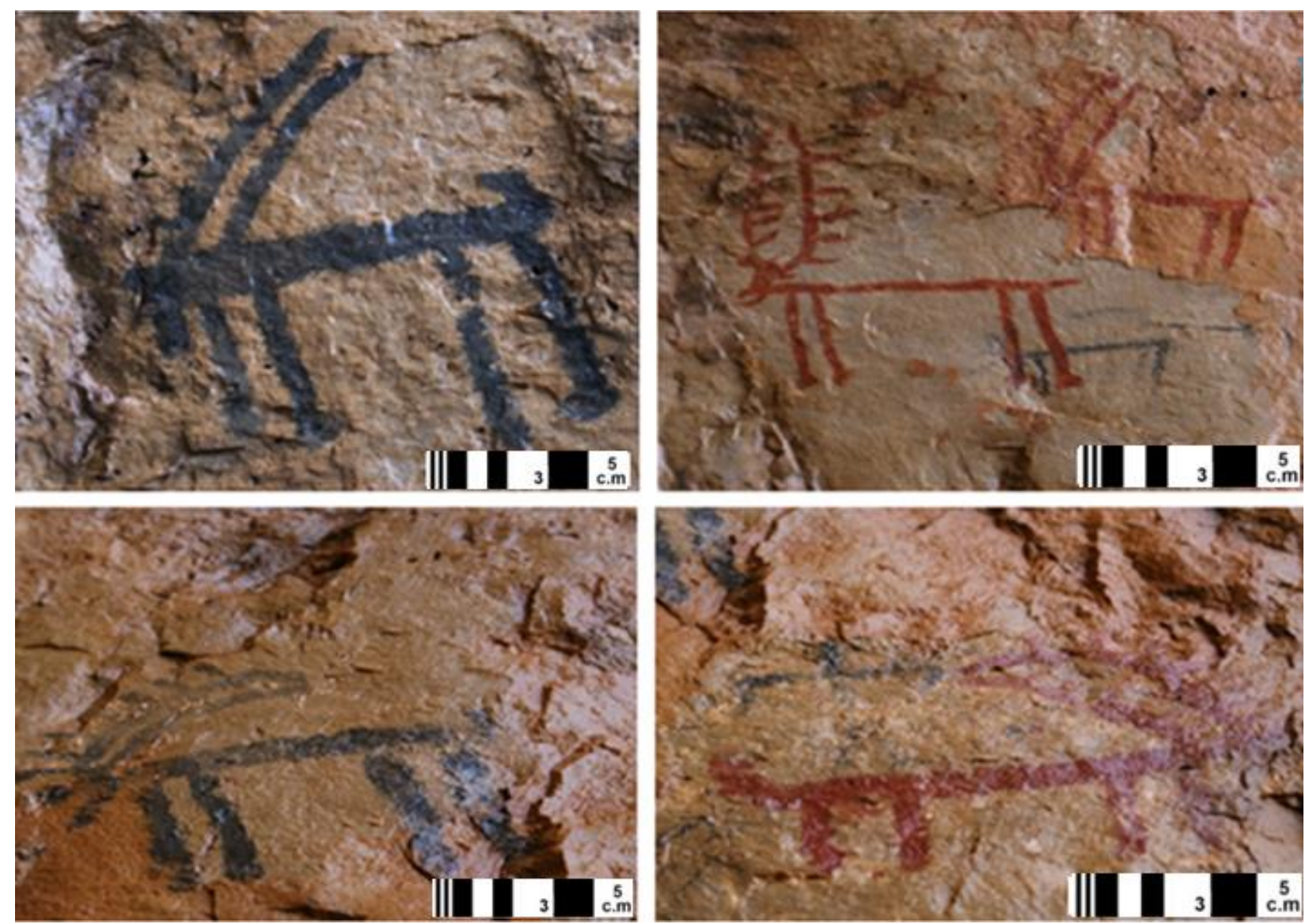

Figure 4. "Ibex" with long and curved or jag horns motifs in the Shamsali Rock shelter.
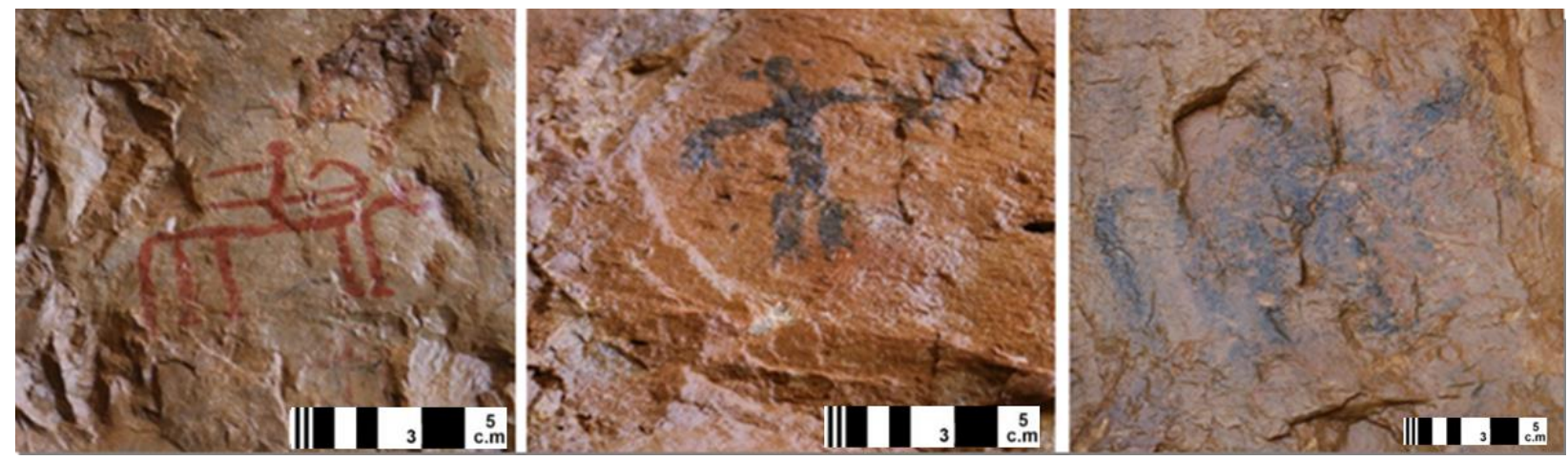

Figure 5. "Anthropomorphic" motif, "Horse rider" and foot in Shamsali Rock shelter.

\section{Gorgali Rock Shelter}

The Gorgali rock shelter is located 150 m north of Kamak Tileh Gorg Village in Loudab district of Bouire Ahmad suburb, Kohgiluye Bouier Ahmad Province. Geographically, it lies $1930 \mathrm{~m}$ above sea level. The rock shelter is $7.60 \mathrm{~m}$ long, $7 \mathrm{~m}$ wide and $12 \mathrm{~m}$ high (Figure 6). Twenty-nine motifs have been identified inside the rock shelter on its northern, northwestern and western walls. They are black, and highly stylized. Some of the images are more accurate but others crudely show human and animal figures. Most of the motifs of the rock shelter are "ibexes" and "anthropomorphic"; the most important one is a "victorious rider" and people with native cloths similar to those worn today in the area (Figure 
7). Among the most important destructions of the reliefs are paginations; some of them are covered in paled sediment formation, and memories written in charcoal.
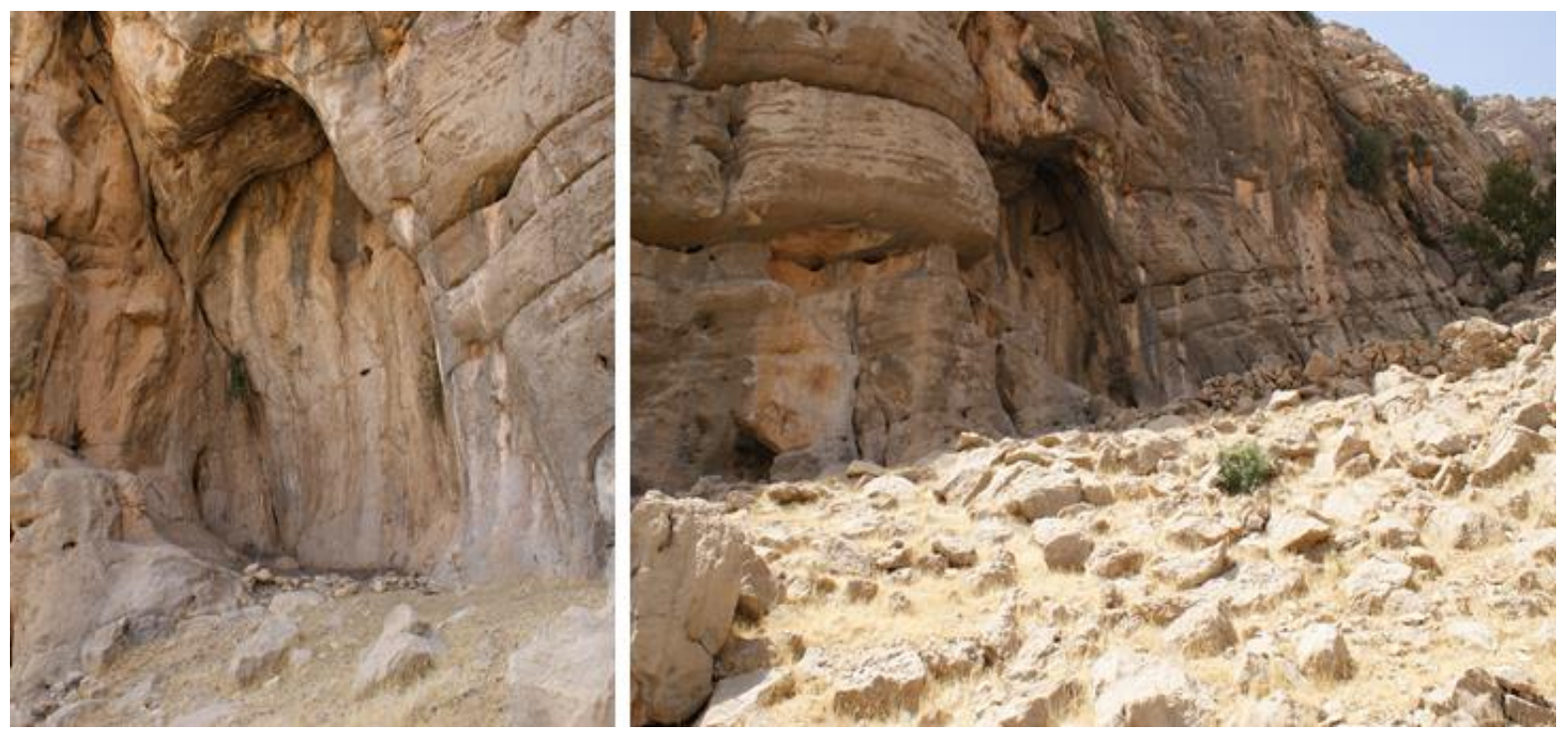

Figure 6. View of Eshkaft-e-Gorgali.

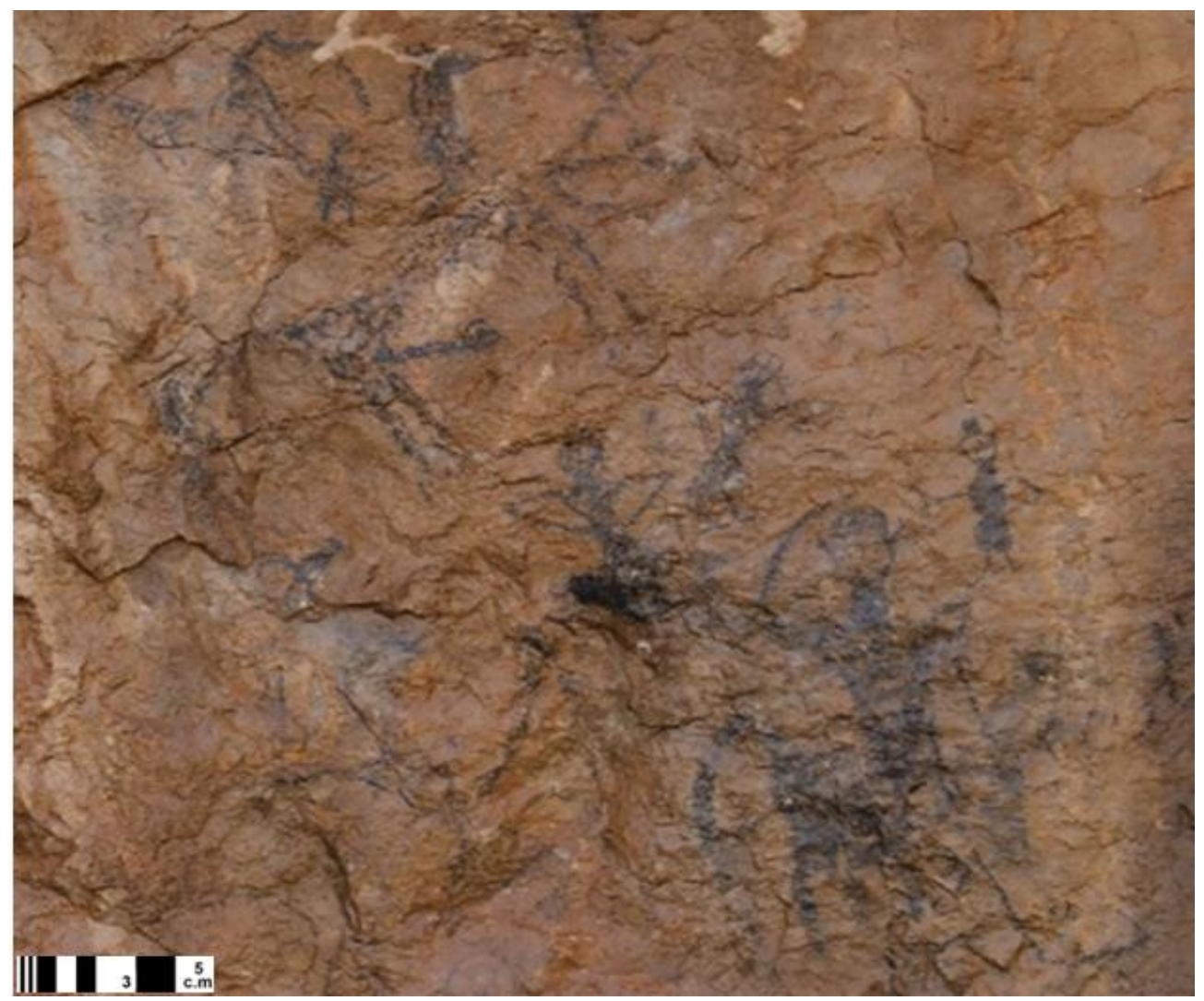

Figure 7. The main group of Pictograms in Eshkaft-e-Gorgali.

\section{Conclusions}

In view of the small number of identified rock painting sites in Iran, the examination of the paintings of Shamsail and Gorgali rock shelters seems important. The Shamsail and Gorgali rock 
shelters with colored motifs were identified on an archaeological survey in Loudab of Kohgiluye Bouier Ahmad province. Considering that few colored motifs have been identified in Iran, these two rock shelters with color motifs are important. In total, 50 motifs have been identified in these two rock shelters, some of which were painted in red and some in black. The motifs in these two rock shelters are mostly "ibexes" and "anthropomorphic horse riders" which are exposed individually or in a flock. The paintings were presumably made by a hunting community, as several of the scenes illustrate the same subject matter. Some believe that the paintings date back to a pre-Historic period, but dating of the motifs needs laboratory studies which unfortunately cannot be carried out in Iran and therefore a chronology has not yet been presented for colored motifs of this area.

\section{Acknowledgments}

We would like to appreciate R. Bednarik, S. Alibeigi, and M. Shaabani; for giving their valuable suggestions and A. Biglari for editing the English manuscript.

\section{Author Contributions}

All authors have contributed equally to this paper.

\section{Conflicts of Interest}

The authors declare no conflict of interest

\section{References}

1. Izadpanah, H. Asâre Bâstâni va Târikhiye Lorestan; Agah: Tehran, Iran, 1984.

2. Izadpanah, H. Naghashihaye Ghar-e Dushe dar Lorestan. Bastan Shenasi va Honar-e Iran 1969b, 4, 53-58.

3. Izadpanah, H. Naghashihaye pish az Tarikh dar Gharhaye Lorestan. Bastan Shenasi va Honar-e Iran 1969a, 3, 6-13.

4. Goff, C. Neglected aspects of Luristan art. Jaarboek van het Genootschap Nederland-Iran Stichting voor Culturele Betrekkingen 1970, 5, 27-37.

5. McBurney, C.B.M. Gozaresh-e Moghadamati Barresi va Haffari dar Gharhay Kuhdasht-e Lorestan Baray Taein Tarikhe Naghashihay Pishaztaikhi Lorestan (transl. by Z. Rahmatyan). Bastan Shenasi va Honar-e Iran 1969, 3, 14-16.

6. Adeli, J.; Garazhian, O.; Yazdi, L.P. Recent pictograms of Homian. J. Anthropol. 2001, 2, 84-101.

7. Asadi, A. Eshkaft-e Ahoo: Panahgahi sakhe-ee dar Bastak (Hormozgan). Bastanpazhohi 2007, 3, 65-70.

8. Biglari, F.; Bisotuni, A.M.M.; Jamshidi, F. Gozaresh-e Barresi Noghosh Ghar-e Cheshme Sohrab, Kermanshah. Bastanpazhohi 2007, 3, 50-54.

9. Ghasimi, T.; Barfi, S.; Nouruzi, R. New Found Pitograms from Abdozou Rock Shelter, Firouz Abad, Southern Zagros. Iran. Archaeol. 2010, 1, 17-26.

10. Shrinsabzadeh, F. Rock-Art of Mir Malas, Iran. Can. Soc. Sci. 2012, 8, 127-131. 
11. Fazel, L.; Alibaigi, S. Discovery of cave art in the province of Fars, Southern Iran. Rock Art Res. 2012, 29, 187-190.

12. Karimi, E. The Rock Paintings of Kuh-e-Donbeh in Esfahan, Central Iran. Arts 2014, 3, 118-134.

13. Vahdati Nasab, H.; Rezaei, M.H.; Naderi, R.; Helak, A Palaeolithic cave cpmplex featuring rock art along the northern shore of Parishan Lake, Fars province, Iran. Name-ye Pazhuheshgah. Journal of the Research Institute of I.C.H.T.O. 2008, 22/23, 91-96.

14. Vahdati, A.A. Stone Canvases: A Preliminary Report on the Study of Two Rock-Art Complexes in North Khorasan Province, Northeastern Iran; I.C.H.T.O Publishing: Khorasan-e-Shomali, Iran, 2010.

15. Sarhaddi, F. Pictograph and Petroglyphs of Saravan (Sistan-Baluchistan, Iran). Ancient Asia 2013, 4, 1-8, doi:http://dx.doi.org/10.5334/aa.12312.

16. Bewley, R.H. The Cambridge University archaeological expedition to Iran 1969. Excavations in the Zagros Mountains: Houmian, Mir Malas and Barde Spid. IRAN 1984, 22, 1-38.

17. Otte, M.; Adeli, J.; Remacle, L. Art rupestre de l'ouest iranien. INORA 2003, 37, 8-12.

18. Remacle, L.; Adeli, J.; Lejeune, M.; Mohamadi, S.; Otte, M. New field Research on Homian Rock-art, Luristan province, Iran. Bastanpazhohi 2007, 2(3), 9-17.

19. Remacle, L.; Lejeune, M.M.; Adeli, J.; Mohamadi, S.; Otte, M. Art rupestre de Houmian, province de Luristan, Iran. Anthropozoologica 2006, 41(2), 13-27.

20. Vahdati, A.A. Bomhaye Sangi: Gozaresh-e Barresi do Majmoae Honar Sakhreye dar Ostan-e Khorasan Shomali (Jurbat va Nargesloye Olya); ICHHO, Bojnoord, Iran, 2010.

21. Vahdati Nasab, H.;Rezaei, M.H.; Naderi, R.; Smith, L.C. Helak, a Paleolithic cave complex featuring rock art along the northern shore of Parishan Lake, Fars province, Iran. Nameh-ye Pazhoheshgah. J. Res. Instit. ICHTO 2008, 22-23, 1-6.

(C) 2015 by the authors; licensee MDPI, Basel, Switzerland. This article is an open access article distributed under the terms and conditions of the Creative Commons Attribution license (http://creativecommons.org/licenses/by/4.0/). 